\title{
Morphology of spermatozoa bound to the zona pellucida of human oocytes that failed to fertilize in vitro
}

\author{
D. Y. Liu and H. W. G. Baker \\ Department Obstetrics \& Gynaecology, University of Melbourne, Reproductive Biology Unit, Royal \\ Women's Hospital, Melbourne, VA 3050, Australia
}

Summary. The morphology of spermatozoa bound to the zona pellucida (ZP) of 264 oocytes that had failed to fertilize in 58 in vitro fertilization procedures was studied by light microscopy. The percentage of spermatozoa with normal morphology bound to the ZP (mean 77, range 8-100) was significantly higher than in the insemination medium (mean 42, range 2-80). The abnormal spermatozoa bound to the ZP had small oval $(47 \%)$, pyriform $(46 \%)$, amorphous $(5 \%)$ and tapering $(2 \%)$ heads. Other abnormalities of morphology were not observed in ZP-bound spermatozoa. The mean rates of binding to the $\mathrm{ZP}$ of spermatozoa with normal morphology (44, $95 \%$ confidence limits $42-46$, number bound $/ \mathrm{ZP} / 10^{5} / \mathrm{ml}$ inseminated) were much higher than for abnormal spermatozoa with small oval $6 \cdot 5(5 \cdot 5-7 \cdot 6)$, pyriform 5.9 $(4 \cdot 8-7 \cdot 3)$, amorphous $1 \cdot 0(0 \cdot 5-2 \cdot 0)$ and tapering $2 \cdot 5(1 \cdot 2-5 \cdot 3)$ heads. The morphologically abnormal forms not found on the ZP were infrequent in the insemination medium (tail defects, large oval, round, pin and duplicate heads and cytoplasmic droplets) but upper $95 \%$ confidence limits for standardized binding ratios of $<60 \%$ indicated that these were unlikely to bind to the zona with rates approaching those of normal spermatozoa (standardized binding ratio 180\%). A large number of uniformly normal spermatozoa bound to the ZP when the percentage normal morphology in the insemination medium was $>40 \%$. The proportions of abnormal spermatozoa on the ZP were significantly correlated with the proportions of abnormal spermatozoa in the insemination medium. Spermatozoon head dimensions were measured with a micrometer in samples from 14 patients. While there were no consistent changes in all samples, the means for head width and area were significantly larger and the ratio of the length to width was smaller for spermatozoa on the ZP than for those in the insemination medium. The head length and ratio of length to width of spermatozoa in samples with good morphology were significantly less than in samples with poor morphology. The percentage of spermatozoa with normal morphology, motility and the ratio of head length to width in the insemination medium were positively correlated with the percentage of spermatozoa with normal morphology bound to the ZP. Logistic regression analysis showed that the diagnosis of tubal infertility and the rate of binding of spermatozoa with normal morphology to the ZP were positively related to fertilization rates in vitro while the rate of binding of spermatozoa with pyriform heads was negatively related. In conclusion, human ZP are highly selective for spermatozoa with normal morphology. The frequency of binding of abnormal spermatozoa to the ZP was mainly dependent on semen quality. Detailed analysis of spermatozoa bound to the ZP should be useful for determining the range of morphology characteristics of spermatozoa with good or poor fertilizing potential. 


\section{Introduction}

A number of studies on the influence of male factors in human in-vitro fertilization (IVF) have shown that the proportion of spermatozoa with normal morphology is significantly related to fertilization rates (Kruger et al., 1986, 1988a; Liu \& Baker, 1988, 1990a; Liu et al., 1988; Chan et al., 1989; Hinting et al., 1990). However, the mechanism of this relationship between spermatozoal morphology and fertility is poorly understood.

In vivo, cervical mucus plays a part in the selection of morphologically normal spermatozoa for further migration through the female reproductive tract (Bergman, 1955; Fredricsson \& Bjork, 1977; Moghissi, 1977; Perry et al., 1977; Hanson \& Overstreet, 1981; Mortimer et al., 1982; Ragni et al., 1985). However, this selection by cervical mucus is not effective against all types of abnormal spermatozoa, in particular, spermatozoa with only abnormal heads can penetrate cervical mucus (Fredricsson \& Bjork, 1977; Mortimer et al., 1982; Ragni et al., 1985). Ahlgren et al. (1974) reported that spermatozoa recovered from the ampulla of the oviduct, fimbria or pouch of Douglas had better morphology than those in the semen. Asch (1976) reported that all spermatozoa recovered from the fimbria and pouch of Douglas were without morphological defects. Although it is not clear what the proportion of spermatozoa with normal morphology is at the fertilization site in vivo, it is certain that cervical mucus and possibly other parts of the female genital tract play a significant role in selection of morphologically normal spermatozoa.

Under conditions of IVF, spermatozoa are added directly to culture medium containing the oocytes after the motile spermatozoa have been selected in the laboratory by swim-up or gradientcentrifugation techniques. Although spermatozoa with normal morphology are preferentially selected because they are more likely to be highly motile, there are still large numbers of morphologically abnormal spermatozoa around the oocyte in the insemination medium (Pousette $e t$ al., 1986; Andolz et al., 1987; Le Lannou \& Blanchard, 1988; Liu et al., 1988). This is particularly true for some male-factor patients who have very poor spermatozoon morphology in the ejaculate (Liu \& Baker, 1988; Liu et al., 1988). Although most of the patients, producing samples with poor morphology, have low $(<25 \%)$ or zero fertilization rates in vitro, a few whose samples have $>90 \%$ morphologically abnormal spermatozoa still have most or all of the oocytes fertilized (Liu \& Baker, 1988, 1990a; Liu et al., 1988). Therefore, the question arises - can abnormal spermatozoa bind to, penetrate and fertilize human oocytes under in vitro conditions?

Early studies of Soupart \& Strong (1974) and Sundstrom (1984) on the interaction between human gametes using scanning and transmission electron microscopy suggested that while a few abnormal spermatozoa could bind to the zona pellucida (ZP), only normal spermatozoa could penetrate the ZP. Sathananthan et al. (1986) reported that some abnormal spermatozoa were observed within the ZP. However, the frequencies of normal and abnormal spermatozoa bound to the ZP were not studied in detail because the electron microscopy methods were limited to examining small numbers of oocytes and spermatozoa.

Studying the morphological status of spermatozoa bound to the ZP at the light microscopy level may provide useful information to improve routine assessment of spermatozoon morphology. In the present study, we evaluated the morphology of spermatozoa, bound to the ZP of oocytes which had failed to fertilize in vitro, using light microscopy and measurement of head dimensions. The relationships between the morphology of spermatozoa in the insemination medium and bound on the ZP, spermatozoon-ZP binding rates and fertilization rates have been analysed.

\section{Materials and Methods}

Patients. Investigations were performed on 58 couples who underwent IVF at the Royal Women's Hospital between May and October 1989. When the woman's oocytes were inseminated with the partner's spermatozoa, some or all of the oocytes failed to fertilize and there was an aggregate total of more than five spermatozoa bound to these oocytes when examined under an inverted phase contrast microscope with magnification of $250 \times$. Diagnoses for the 
couples were unexplained infertility (13 couples), male-factor infertility (11), tubal occlusion (17) and endometriosis (5). The remaining patients had more than one diagnosis in the following combinations: tubal occlusion with male factor (5), endometriosis with male factor (7). Male infertility was present in $23(40 \%)$ of couples. The diagnoses were determined before IVF was performed.

In-vitro fertilization. Multiple follicular development was induced with clomiphene citrate (CC) and human menopausal gonadotrophin (hMG) $-100 \mathrm{mg} \mathrm{CC}$ was given daily for 5 days starting 10 days before the calculated midpoint of the cycle and 150 to 225 units hMG i.m. daily starting the day after CC. Doses of hMG were based on urinary oestrone measurements and increased if necessary to a maximum of 300 units/day. Human chorionic gonadotrophin (hCG) was given by injection and oocyte collection performed by vaginal ultrasound-guided aspiration $34-36 \mathrm{~h}$ after hCG injection or at the estimated time of commencement of spontaneous LH surges. Semen was collected by masturbation $2 \mathrm{~h}$ before the expected time of insemination and the motile spermatozoa prepared by a swim-up technique. Approximately 100000 spermatozoa were added to each oocyte in $1 \mathrm{ml}$ of culture medium in a plastic multiwell tray. Higher concentrations of spermatozoa (up to $600000 / \mathrm{ml}$ ) were used when possible for patients with male-factor infertility, particularly those producing spermatozoa with poor morphology. Fertilization was assessed $18-20 \mathrm{~h}$ later and embryos transferred to the uterine cavity $40-45 \mathrm{~h}$ after insemination. Oocytes that had apparently failed to fertilize were re-examined at 48 and $60 \mathrm{~h}$ after insemination before concluding that fertilization had not occurred.

Assessment of morphology of spermatozoa in the insemination medium and when bound to the oocytes that failed to fertilize. Oocytes that showed no evidence of either two pronuclei or cleavage $60 \mathrm{~h}$ after insemination were used for this study. There were 11 couples with all oocytes failing to fertilize. Spermatozoa in the culture medium from wells in which oocytes failed to fertilize were pooled for each patient. The spermatozoal suspensions were centrifuged at $600 \mathrm{~g}$ for $5 \mathrm{~min}$ and the supernatant was removed. The pellet was resuspended to $20 \mu \mathrm{l}$ of the medium and smeared on a glass slide. For spermatozoa bound to the ZP, all unfertilized oocytes were pooled and washed in protein-free normal saline. The washed oocytes were transferred to a glass slide with a micropipette and the oocytes were flattened between two glass microscope slides. The slides were then separated and, in most cases, half the ZP of each oocyte was stuck to the surface of each slide. The position of the zonae on the slide was labelled immediately using a glass pen to aid finding them under the microscope. The slides for spermatozoa in the insemination medium and on the ZP were airdried and stained by the Shorr method (Jeulin et al., 1986; Liu et al., 1988). The morphology of 200 spermatozoa from the insemination medium and all spermatozoa bound to the ZPs were assessed under oil immersion at a magnification of $\times 1000$ using bright field illumination. An example of morphology of spermatozoa bound to a ZP is shown in Fig. 1 .

Assessment of spermatozoa morphology was based on the criteria of the World Health Organization (1987). Each spermatozoon was assigned to one morphological category only with the priority order-head defects, tail defects and midpiece defects: spermatozoa without any defects were classified as normal. A few $(<3 \%)$ spermatozoa bound to the ZP were difficult to score because of damage or because they were seen on edge or were otherwise not lying flat in the plane of focus; these spermatozoa were not counted.

Measurement of head dimensions of spermatozoa. The width and length of the head of spermatozoa in the insemination medium and bound to the zonae from 14 patients were estimated to the nearest $0.1 \mu \mathrm{m}$ using an eyepiece micrometer with graduations of $1 \mu \mathrm{m}$. The slides used in this study were selected according to the spermatozoal morphology in the insemination medium: 7 had a poor morphology (normal $<25 \%$ ) and 7 had good morphology (normal $>25 \%$ ), and there were more than 50 spermatozoa on the zonae. The spermatozoon closest to the centre cross of the micrometer in each field was measured. Fields were changed by moving the slide randomly without repeating measurements on the same spermatozoa. Fifty spermatozoa were assessed in the insemination medium and 50 on the ZP for each patient. The ratio of length to width (length/width) and the area of the enclosing rectangle (length $\times$ width) of the heads were calculated.

Statistical analysis. As the probability of spermatozoa binding to the ZP will follow a Poisson distribution (Aitken \& Elton, 1984), weighted mean rates of binding per ZP of spermatozoa of the different morphological categories per unit concentration inseminated $\left(\times 10^{5} / \mathrm{ml}\right)$ and the $95 \%$ confidence limits were calculated from the total number of spermatozoa counted on the zonae. Standardized binding ratios were also calculated to demonstrate the relative differences between the binding of the morphological categories based on the possibility that all types of spermatozoa would have an equal chance of binding to the ZP (Armitage \& Berry, 1987). The confidence limits of these ratios were calculated from the expected total number of spermatozoa bound to the zonae. Correlations between spermatozoon characteristics in the insemination medium, ZP binding rates of spermatozoa and fertilization rates in vitro were examined by Spearman (non-parametric) tests. Differences of head dimensions of spermatozoa in the insemination medium and on the ZP were examined by two-way analysis of variance and for those with good and poor morphology in the insemination medium by contrasts between groups in one-way analyses of variance. Comparison of sperm characteristics for patients with no or some oocytes fertilized were performed by $t$-test. Logistic regression analysis was used to determine which combinations of the tests were independently related to fertilization rate. Statistical tests were performed using the computer package SPIDA (Macquarie University, Sydney, Australia). 

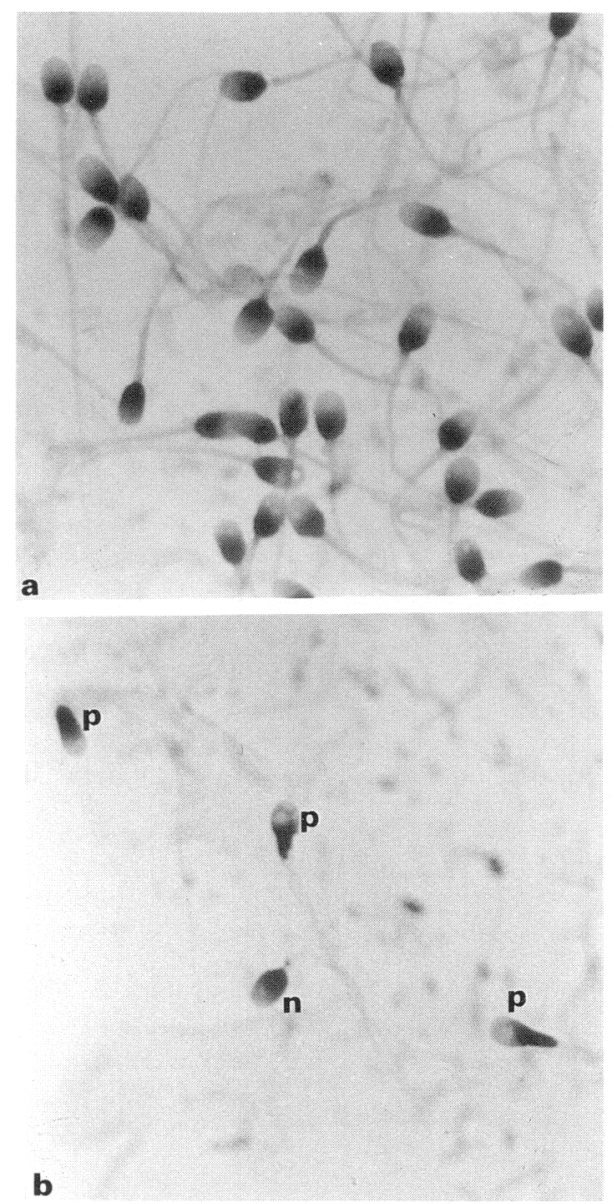

b

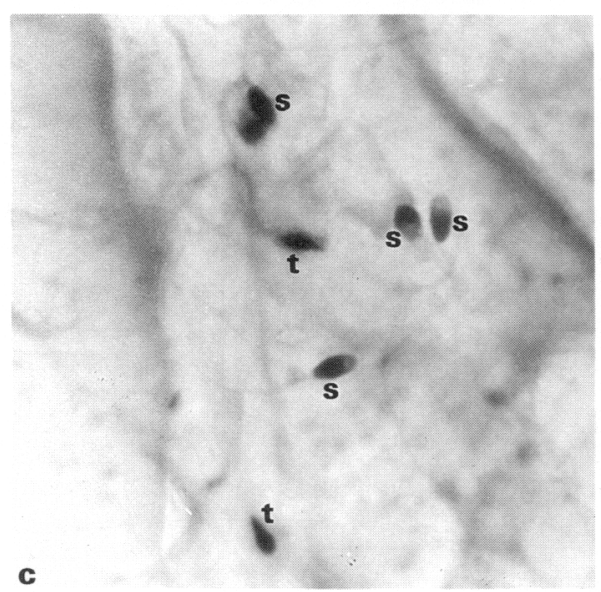

Fig. 1. Morphology of spermatozoa bound to the zona pellucida. (a) All spermatozoa with normal morphology. $(b, c) n=$ normal; $p=$ pyriform; $s=$ small oval; $t=$ tapering heads or possibly penetrating spermatozoa without acrosomes. (Shorr stain, micrographed with $\times 100$ oil immersion lens). 


\section{Results}

\section{IVF results, spermatozoon characteristics and numbers bound to ZP}

There were very wide ranges for all the spermatozoon test results and numbers of spermatozoa bound to the ZP and the numbers of ZP examined for patients with either none or some oocytes fertilized (Table 1). There was a significantly higher proportion of spermatozoa with normal morphology in both insemination medium and bound to the ZP for patients with some oocytes fertilized than those with no oocytes fertilized. Although patients with zero fertilization rates had significantly higher numbers of spermatozoa used for insemination than patients with some fertilization, they had significantly lower numbers of spermatozoa bound to the ZP. Eleven patients had less than 25 and 13 had more than 100 spermatozoa bound per ZP.

Table 1. Results of in vitro fertilization and spermatozoa tests and numbers of spermatozoa bound to zonae pellucidae $(\mathrm{ZP})$ in patients with zero $(n=11)$ or some $(n=47)$ oocytes fertilized

\begin{tabular}{lccccc}
\hline & \multicolumn{2}{c}{$\begin{array}{c}\text { No oocytes } \\
\text { fertilized }\end{array}$} & \multicolumn{2}{c}{$\begin{array}{c}\text { Some oocytes } \\
\text { fertilized }\end{array}$} \\
\cline { 2 - 5 } & Mean & Range & Mean & Range \\
\cline { 5 - 6 } & $9 \cdot 8$ & $3-21$ & $10 \cdot 4$ & $2-25$ \\
Oocytes inseminated & 0 & 0 & $6 \cdot 5$ & $1-19^{* *}$ \\
Oocytes fertilized & 0 & 0 & 59 & $10-92^{* *}$ \\
Fertilization rate (\%) & 249 & $95-600$ & 136 & $50-440^{*}$ \\
Spermatozoa concn (insem. 10 $3 / \mathrm{ml}$ ) & 71 & $1-99$ & 80 & $20-99$ \\
Motility (insem. \%) & 29 & $4-46$ & 45 & $2-80^{*}$ \\
Normal morphology (insem. \%) & $7 \cdot 6$ & $2-12$ & 3.9 & $1-20^{*}$ \\
No. ZP per patient & 46 & 14100 & 85 & $7.329^{*}$ \\
Total no. spermatozoa on ZP & 19 & $4-100$ & 36 & $1-222^{*}$ \\
Mean no. spermatozoa bound/ZP & & & &
\end{tabular}

Insem., insemination medium.

${ }^{*} P<0.01 ;{ }^{* *} P<0.001$ ( $t$-test).

\section{Morphology of spermatozoa and differential binding to the ZP}

Table 2 shows mean and range of percentages of various morphological categories of spermatozoa and the numbers of subjects with any spermatozoa in each category in the insemination medium and bound to the ZP. In three subjects the spermatozoa bound to ZP were classified as tapering ( 2 of 18) or amorphous heads ( 1 of 46 and 3 of 222), when none of these forms was detected among the 200 spermatozoa examined from the insemination medium; these spermatozoa have been omitted from the analysis. Spermatozoa with normal morphology bound to ZP more frequently than did those with abnormalities. However, some abnormal spermatozoa bound to the ZP; these had small oval, pyriform, tapering and amorphous heads. Of the $22.7 \%$ of abnormal forms on the ZP, $47 \%$ had small oval, $46 \%$ pyriform, $5 \%$ amorphous and $2 \%$ tapering heads. Although many other types of abnormal spermatozoa (tail defects, large oval, round and pin heads, duplicate tails and heads, and cytoplasmic droplets) were present in the insemination medium, these forms were not seen on the ZP.

Table 3 shows that there was a significantly greater rate of binding of spermatozoa with normal morphology to the ZP than for those with abnormal morphology. The four categories of abnormal forms bound to the ZP had much lower binding rates than did normal forms. The other six categories, which were not found bound to the ZP, were infrequent in the insemination medium and the 
Table 2. Mean (range) percentage of spermatozoa of each morphological category and the number of patients having any spermatozoa in the category $(n)$ in the insemination medium and bound to the zona pellucida (ZP)

\begin{tabular}{|c|c|c|c|c|}
\hline \multirow{2}{*}{$\begin{array}{l}\text { Morphological } \\
\text { category }\end{array}$} & \multicolumn{2}{|c|}{ Insemination medium } & \multicolumn{2}{|l|}{$\mathrm{ZP}$} \\
\hline & Mean (range) & $n$ & Mean (range) & $n$ \\
\hline Normal & $42 \cdot 4 \quad(2-80)$ & 58 & $77 \cdot 3(8-100)^{*}$ & 58 \\
\hline Small oval & $24 \cdot 7(10-50)$ & 58 & $10 \cdot 7(0-50)^{*}$ & 50 \\
\hline Pyriform & $16 \cdot 2(2-44)$ & 58 & $10.5(0-65)^{*}$ & 47 \\
\hline Amorphous & $4 \cdot 1 \quad(0-50)$ & 40 & $1 \cdot 1(0-14)^{*}$ & 9 \\
\hline Tapering & $2 \cdot 1 \quad(0-15)$ & 48 & $0.5(0-11)^{*}$ & 9 \\
\hline Tail defects & $6.8 \quad(0-20)$ & 53 & 0 & 0 \\
\hline Large oval & $1.8(0-6)$ & 47 & 0 & 0 \\
\hline Round & $0.9 \quad(0-9)$ & 24 & 0 & 0 \\
\hline Pin & $0 \cdot 3 \quad(0-4)$ & 11 & 0 & 0 \\
\hline Duplicate head & $0.5 \quad(0-2)$ & 21 & 0 & 0 \\
\hline Cytoplasmic droplet & $0.4(0-3)$ & 12 & 0 & 0 \\
\hline
\end{tabular}

${ }^{*} P<0.01 ;$-test.

Table 3. Rates of binding of spermatozoa of different morphological categories of zonae pellucidae (ZP) in humans

\begin{tabular}{|c|c|c|}
\hline $\begin{array}{l}\text { Morphological } \\
\text { category }\end{array}$ & $\begin{array}{c}\text { Mean binding rate } \\
\text { spermatozoa } / \mathrm{ZP} / 10^{5} / \mathrm{ml}\end{array}$ & $\begin{array}{c}\text { Standardized binding } \\
\text { ratio } \%\end{array}$ \\
\hline All spermatozoa & $18.7(17.9-19.6)$ & 100 \\
\hline Normal & $44 \cdot 2(42 \cdot 0-46 \cdot 5)$ & $180(175-184)$ \\
\hline Small oval & $6 \cdot 5(5 \cdot 5-7 \cdot 6)$ & $38(32-44)$ \\
\hline Pyriform & $5 \cdot 9 \quad(4 \cdot 8-7 \cdot 3)$ & $54(47-62)$ \\
\hline Amorphous & $1.0 \quad(0.5-2 \cdot 0)$ & $20 \quad(6-35)$ \\
\hline Tapering & $2 \cdot 5 \quad(1 \cdot 2-5 \cdot 3)$ & $(1-42)$ \\
\hline Tail defects & 0 & $(0-12)$ \\
\hline Large oval & 0 & $(0-21)$ \\
\hline Round & 0 & $(0-34)$ \\
\hline Pin & 0 & $(0-54)$ \\
\hline Duplicate heads & 0 & $(0-40)$ \\
\hline Cytoplasmic droplet & 0 & $(0-46)$ \\
\hline
\end{tabular}

$95 \%$ confidence limits in parentheses.

confidence limits for the standardized binding ratios are wide. However, the upper confidence limits indicate that it is unlikely that any of these types of spermatozoa would bind to ZP at rates approaching those of normal spermatozoa.

\section{Correlation between morphology of spermatozoa bound to the ZP and other spermatozoal characteristics}

When normal morphology in the insemination medium was greater than $40 \%$, more spermatozoa bound to the ZP and most had normal morphology. Lower numbers of spermatozoa bound and more had abnormal morphology on the $\mathrm{ZP}$ when normal morphology in the insemination medium was less than $15 \%$ (Figs 1 and 2). However, even with the four patients producing samples with the lowest normal morphology in the insemination medium (mean 6, range 2-9\%), the percentage of spermatozoa on the ZP with normal morphology (mean 30, range 8-39\%) was significantly increased. The percentage normal spermatozoon morphology (Fig. 2, Spearman $r=0 \cdot 778$; 
$P<0.001$ ) and motility (Spearman $r=0.392 ; P<0.01$ ) in the insemination medium were highly significantly correlated with percentage normal morphology of spermatozoa bound to the ZP. There was a significant correlation between the percentage of motile spermatozoa in the insemination medium and the rate of binding of normal spermatozoa to the ZP (Spearman $r=0 \cdot 362$; $P<0.01)$. The binding rate was significantly lower in patients with the diagnosis of male-factor infertility than in those with other diagnoses $(P<0 \cdot 01)$.

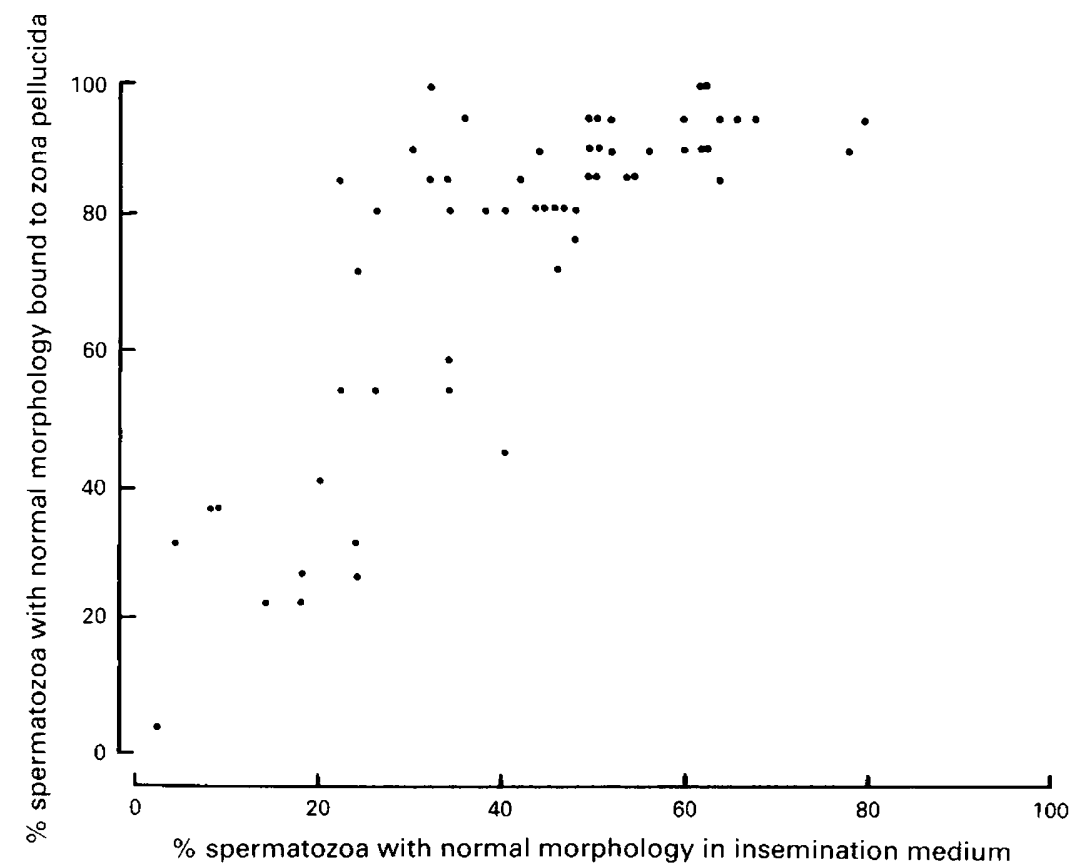

Fig. 2. Correlation between percentage of human spermatozoa with normal morphology in the insemination medium and bound to the zona pellucida (Spearman $r=0.778 ; P<0.001$ ).

\section{Head dimensions of spermatozoa in the insemination medium and bound on the ZP}

The mean head dimensions of spermatozoa in the insemination medium and on the ZP were significantly different for most of the 14 subjects studied (Fig. 3). Overall head width and area were significantly greater for spermatozoa bound to the ZP than for spermatozoa in the insemination medium and the ratio of head length to width was smaller (Table 4). The mean head length of spermatozoa bound to the ZP was not significantly different from that in the insemination medium. However, there appeared to be no consistent pattern and some patients had the opposite changes (Fig. 3). There were significant correlations between mean length (Spearman $r=0.873 ; P<0.01$ ), width (Spearman $r=0.792 ; P<0.01$ ), area (Spearman $r=0.619 ; P<0.05$ ) and ratio (Spearman $r=0.958 ; P<0.001)$ for the heads of spermatozoa in the insemination medium and bound to the $Z P$ from the same patients.

The 14 patients were selected according to the morphology of spermatozoa in the insemination medium. Numbers 1-7 had good morphology and 8-14 poor morphology (Fig. 3). The head length was longer, width shorter and the ratio of length to width greater for spermatozoa in the insemination medium and on the ZP in patients with poor morphology compared with those for patients 

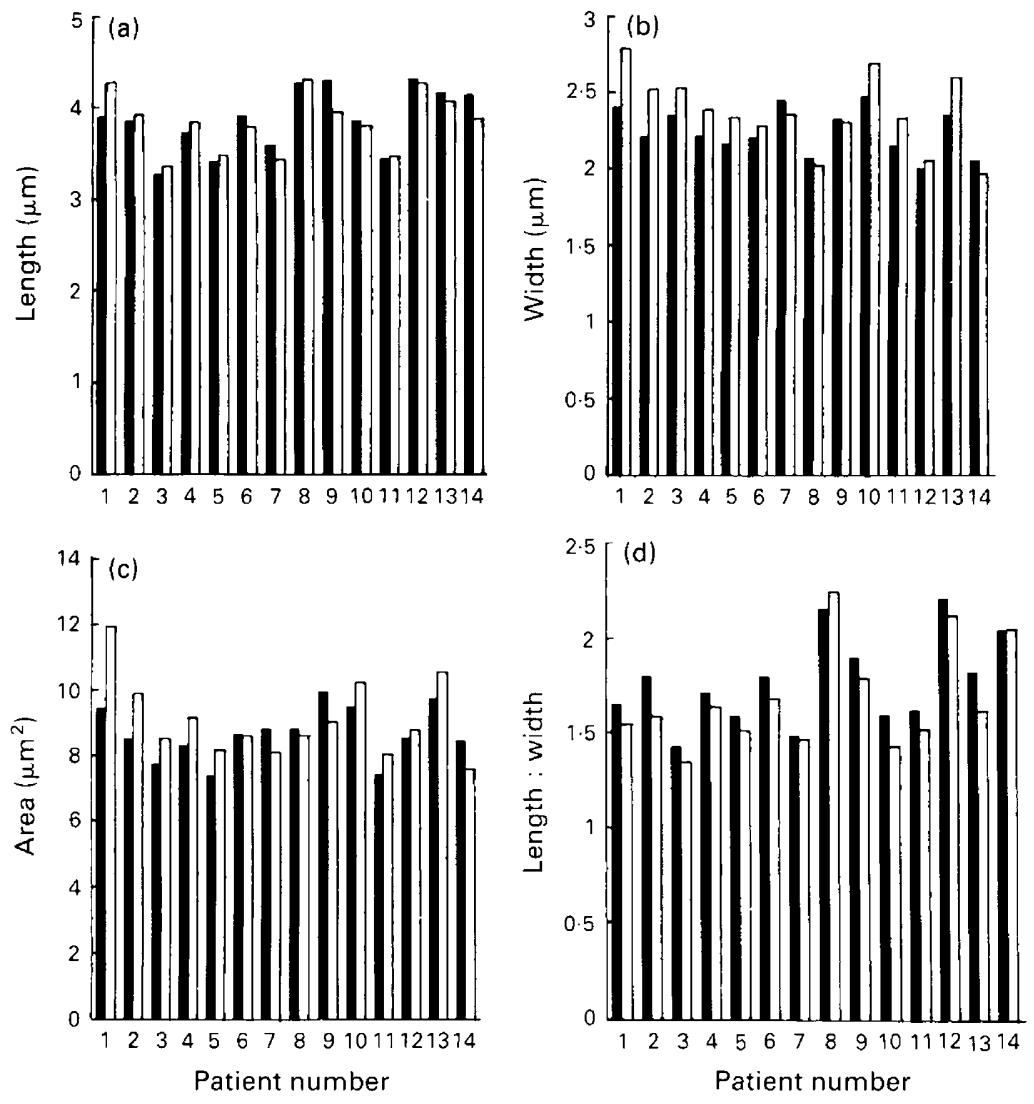

Fig. 3. Mean head (a) length, (b) width, (c) area and (d) ratio of length to width of the heads of human spermatozoa in the insemination medium ( $\boldsymbol{\square})$ and bound to the zona pellucida $(\square)$. Patients $1-7$ had $<25 \%$ spermatozoa with normal morphology in insemination medium; patients $8-14>25 \%$.

Table 4. Comparison of head dimensions of spermatozoa in the insemination medium and bound to the zonae pellucidae (ZP). 100 (50 in insemination medium and 50 bound to the ZP) spermatozoa measured from each of 14 patients

\begin{tabular}{lcll}
\hline \multirow{2}{*}{$\begin{array}{l}\text { Head } \\
\text { dimensions }\end{array}$} & Insemination medium & & Bound to ZP \\
\cline { 2 - 2 } & Mean (range) & & Mean (range) \\
\hline Length $(\mathrm{L}, \mu \mathrm{m})$ & $3 \cdot 9(2 \cdot 0-7 \cdot 0)$ & & $3 \cdot 8(2 \cdot 0-6 \cdot 0)$ \\
Width $(\mathrm{W}, \mu \mathrm{m})$ & $2 \cdot 2(1 \cdot 1-5 \cdot 1)$ & & $2 \cdot 4(1 \cdot 1-4 \cdot 3)^{*}$ \\
Area $\left(\mathrm{L} \times \mathrm{W}, \mu \mathrm{m}^{2}\right)$ & $8 \cdot 6(3 \cdot 6-21 \cdot 0)$ & & $9 \cdot 1(4 \cdot 0-17 \cdot 0)^{*}$ \\
Ratio $(\mathrm{L} / \mathrm{W})$ & $1 \cdot 8(0 \cdot 8-3 \cdot 6)$ & & $1 \cdot 7(0 \cdot 8 \cdot 4 \cdot 6)^{*}$ \\
\hline
\end{tabular}

${ }^{*} P<0.001$ (analysis of variance).

with good morphology. The head area of spermatozoa in the insemination medium was significantly larger in the poor morphology group than in the good morphology group. However, there was no significant difference in the head area of spermatozoa bound to the ZP between the two groups (Table 5). 
Table 5. Comparison of mean (range) head dimensions of spermatozoa with good (normal $>25 \%$, seven patients) and poor (normal $<25 \%$, seven patients) morphology in the insemination medium and bound to the zona pellucida

\begin{tabular}{|c|c|c|}
\hline & $<25 \%$ & $>25 \%$ \\
\hline & Mean (range) & Mean (range) \\
\hline \multicolumn{3}{|l|}{ In insemination medium } \\
\hline$\%$ Spermatozoa with normal morphology & $11(2-23)$ & $54(27-80)^{*}$ \\
\hline Length $(\mu \mathrm{m})$ & $4 \cdot](2 \cdot 0-7 \cdot 0)$ & $3 \cdot 7(2 \cdot 0-6 \cdot 1)^{*}$ \\
\hline Width $(\mu \mathrm{m})$ & $2 \cdot 2(1 \cdot 2-5 \cdot 1)$ & $2 \cdot 4(1 \cdot 1-3 \cdot 1)^{*}$ \\
\hline Ratio $(\mathrm{L} / \mathrm{W})$ & $1.9(0.8-3 \cdot 9)$ & $1.6(1.0-3.6)^{*}$ \\
\hline Area $\left(\mathrm{L} \times \mathrm{W}, \mu \mathrm{m}^{2}\right)$ & $8.9(4 \cdot 0-20 \cdot 9)$ & $8.4(3.6-18 \cdot 0)^{*}$ \\
\hline \multicolumn{3}{|l|}{ Bound to zona pellucida } \\
\hline$\%$ Spermatozoa with normal morphology & $32 \quad(8-54)$ & $92(8398)^{*}$ \\
\hline Length $(\mu \mathrm{m})$ & $4 \cdot 0(2 \cdot 0-6 \cdot 0)$ & $3 \cdot 7(2 \cdot 0-5 \cdot 0)^{*}$ \\
\hline Width $(\mu \mathrm{m})$ & $2 \cdot 3(1 \cdot 1-4 \cdot 0)$ & $2 \cdot 5(1.5-4 \cdot 3)^{*}$ \\
\hline Ratio $(\mathrm{L} / \mathrm{W})$ & $1 \cdot 8(0 \cdot 8-4 \cdot 6)$ & $1 \cdot 5(0 \cdot 9-2 \cdot 3)^{*}$ \\
\hline Area $\left(\mathrm{L} \times \mathrm{W}, \mu \mathrm{m}^{2}\right)$ & $9 \cdot 0(4 \cdot 2-15 \cdot 4)$ & $9 \cdot 2(4-17 \cdot 5)^{*}$ \\
\hline
\end{tabular}

${ }^{*} P<0.00$ l (analysis of variance).

\section{Correlation between spermatozoon morphology and other variables and fertilization rates in vitro}

There were strong relationships between fertilization rates and the proportions of both spermatozoa with normal morphology in the insemination medium (Fig. 4a; Spearman $r=0.566$; $P<0.001$ ) and on the ZP (Fig. 4b; Spearman $r=0.533 ; P<0.001$ ). The patients, in which $<70 \%$ of spermatozoa bound to the ZP had normal morphology, had low $(<50 \%)$ or zero fertilization rates (Fig. $4 \mathrm{~b}$ ). These patients often had low numbers of spermatozoa bound to the $Z P$. The patient producing samples with the lowest percentage normal morphology on the ZP ( 7 of 81 ( $8 \%$ ) spermatozoa bound to 3 zonae) had 5 of 11 oocytes fertilized and most of the abnormal spermatozoa on the ZP had pyriform heads $(61 \%, 50$ of 81$)$.

The rate of binding of spermatozoa with normal morphology to the ZP (Fig. 5, $r=0.552 ; P=$ $0.001)$, and total rate of ZP binding of spermatozoa of all types $(r=0.642 ; P<0.001)$ were highly significantly correlated with fertilization rates in vitro.

More zonae were examined in the subjects with low fertilization rates $(r=-0.594 ; P<0.001)$ and the mean number of spermatozoa per zona was directly related to the fertilization rates $(r=$ $0.545 ; P<0.001$ ). The percentage motility (Spearman $r=0.286 ; P<0.05$ ) and the ratio of head length to width of spermatozoa (Spearman $r=-0.534 ; n=14 ; P<0.05$ ) in the insemination medium were also significant. The fertilization rate was lower in couples with male-factor infertility $(P<0.01)$ and higher in those with tubal disease $(P<0.01)$.

Logistic regression analysis showed that the rate of binding of normal spermatozoa to the $\mathrm{ZP}$ (regression coefficient, $b=0.014$; standard error (s.e.) $=0.0026 ; z=5.47 ; P<0.001$ ) and the diagnosis of tubal disease $(b=1 \cdot 148$; s.e. $=0.205 ; z=5.60 ; P<0.001)$ were both independently directly related to fertilization rate in vitro (Fig. 5). The rate of binding of spermatozoa with pyriform heads to the $\mathrm{ZP}(b=-0.029 ;$ s.e. $=0.011 ; z=2.64 ; P<0.05)$ was inversely related.

\section{Discussion}

The present study shows that human zonae are highly selective for morphologically normal spermatozoa. Rates of binding were calculated in two ways. The first was based on the average number of spermatozoa of different morphological category counted on the zona and the concentration of the same forms in the insemination medium. The second was based on the calculated 

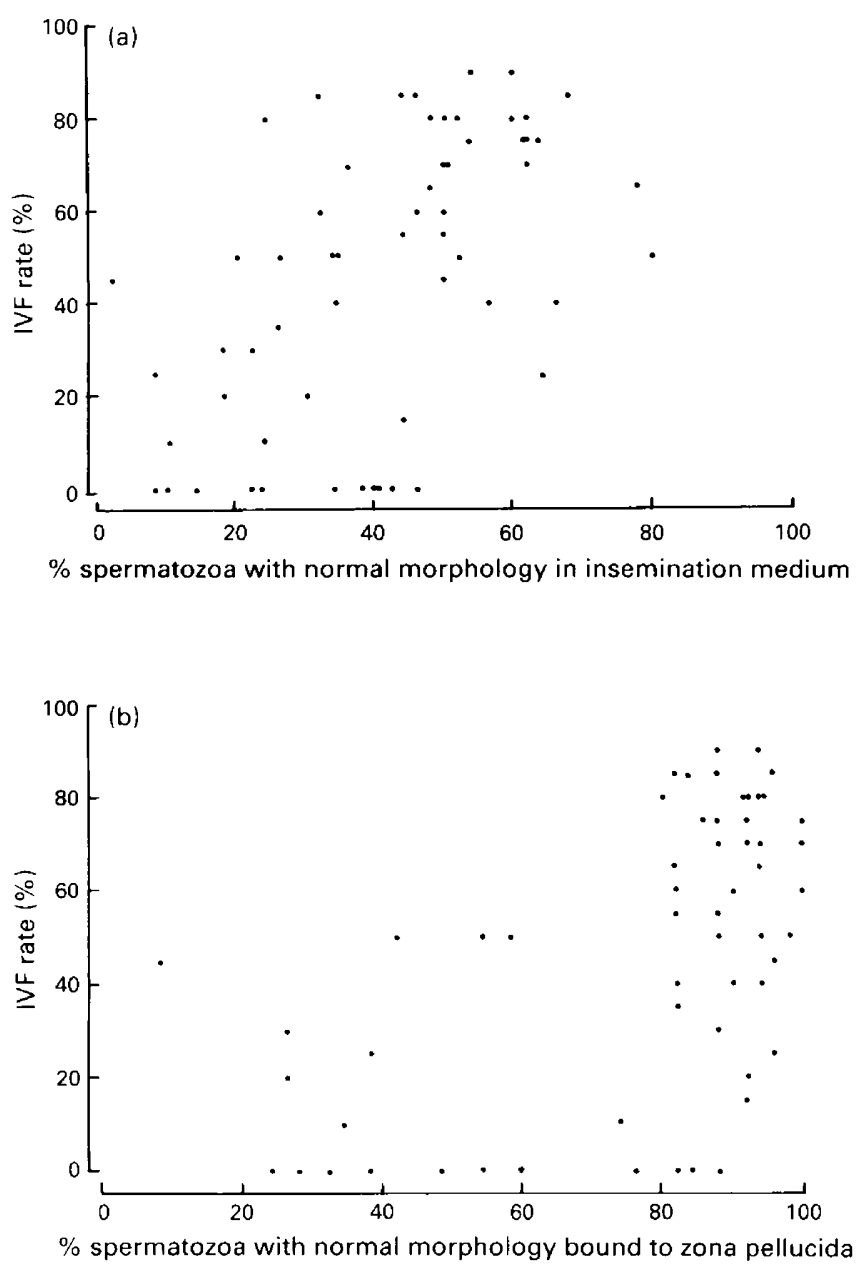

Fig. 4. Correlation between fertilization rate in vitro (IVF) and percentage of human spermatozoa with normal morphology in (a) the insemination medium (Spearman $r=0.566 ; P<0.001$ ) and (b) bound to the zona pellucida (Spearman $r=0.538 ; P<0.001$ ).

expected numbers from the proportion in the insemination medium if all had an equal chance to bind to the zonae. The average binding rate of normal spermatozoa was $44 / Z P / 10^{5}$ normal spermatozoa inseminated. The morphologically abnormal spermatozoa that bound to the ZP did so at much lower rates $\left(<8 / \mathrm{ZP} / 10^{5}\right.$ inseminated) and the proportion of abnormal spermatozoa bound to the $\mathrm{ZP}$ was mainly dependent on the morphology of the spermatozoa in the insemination medium. Most ( $>90 \%$ ) of the abnormal forms of spermatozoa on the ZP had small and pyriform heads and less than $10 \%$ of them had tapering or amorphous heads. All the other abnormal forms, such as tail defects, large, round, pin, and duplicated heads and tails were not seen on the ZP. Although these forms, other than tail defects, were rare in the insemination medium, calculation of the $95 \%$ confidence limits of the standardized binding ratio indicates it is likely that they could not bind to the ZP at rates greater than one-third of those of normal spermatozoa. When spermatozoal suspensions with very low percentages of normal morphology were used for insemination of oocytes, lower numbers of spermatozoa were bound to the ZP. In contrast, when suspensions with high percentages of spermatozoa with good morphology were used for insemination, large numbers of spermatozoa with uniformly good morphology were observed on the $\mathrm{ZP}$. This result is consistent 


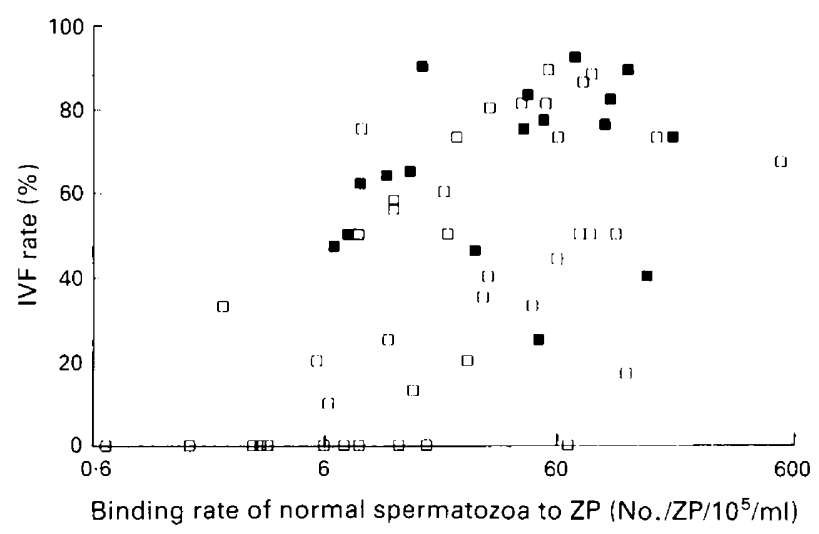

Fig. 5. Correlation between the rate of binding of human spermatozoa with normal morphology to the zona pellucida (ZP) and fertilization rates in vitro. Spearman $r=0.552$; $P<0.001$. ( $\square)$ Patients with tubal disease, ( $\square$ ) patients with other diagnosis.

with our previous findings that the proportion of spermatozoa with normal morphology is strongly correlated with the number of spermatozoa bound to the ZP (Liu et al., 1989a,b).

The abnormal spermatozoa do not have the same ability as normal spermatozoa to bind to the ZP for a variety of reasons. It is probable that they have membrane and acrosome abnormalities, which may directly impair spermatozoa-ZP binding (Dadoune, 1988). We have found that the proportion of spermatozoa with a normal intact acrosome was significantly related to the number of spermatozoa bound to the ZP of human oocytes and fertilization rates in patients producing samples with poor morphology (Liu \& Baker, 1988; Liu et al., 1989a,b). A further study has shown that acrosome-reacted spermatozoa have either no or less ability to bind to the ZP than do acrosome-intact spermatozoa (Liu \& Baker, 1990b). Therefore, the shape of the acrosomal area is probably very important for binding to the zona. It is interesting that the abnormal forms with the highest zona binding rates, small oval and pyriform heads have acrosomal areas of similar shape to those of spermatozoa with normal morphology.

In vivo, spermatozoa with good morphology are partially selected by cervical mucus and other parts of female reproductive tract after semen is deposited into the vagina. However, this selection is limited and does not exclude all the abnormal forms, in particular spermatozoa with abnormal heads (Ahlgren et al., 1974; Mortimer et al., 1982). In vitro, cervical mucus penetration tests show that some abnormal spermatozoa, such as those with small oval and pyriform heads, can penetrate the mucus as well as normal spermatozoa (Jeulin et al., 1985). The morphology status of human spermatozoa at the fertilization sites in vivo is unclear. Under in-vitro fertilization conditions, spermatozoa are usually prepared by swim-up or other techniques. Although these techniques are mainly used to select spermatozoa with better motility, the percentage of spermatozoa of normal morphology is also improved (Pousette et al., 1986; Andolz et al., 1987; Le Lannou \& Blanchard, 1988; Liu et al., 1988; Scott et al., 1989). However, there are still many abnormal spermatozoa in the insemination medium, particularly in cases of male infertility with very poor spermatozoal morphology in the ejaculate (Liu \& Baker, 1988; Liu et al., 1988). The present study shows that small oval and pyriform-headed spermatozoa can bind to the ZP at moderate rates. Whether these types of abnormal spermatozoa may be able to penetrate the zona and fertilize the oocyte is unknown. One patient, with only $8 \%$ normal and $61 \%$ pyriform-headed spermatozoa bound to the $Z P$, had 5 of 11 oocytes fertilized. Analysis of factors affecting fertilization rates showed that the rate of binding to the ZP of spermatozoa with normal morphology was important. It is possible that, even if they penetrate the zona, most of the morphologically abnormal spermatozoa bound to the ZP may not be able to fuse with the oolemma because of the abnormal shape of the equatorial 
segment and postacrosomal region or because of other nuclear abnormalities (Dadoune, 1988; Dadoune et al., 1988).

Soupart \& Strong (1974) and Sundstrom (1984) reported that only normal spermatozoa were found in the ZP by transmission and scanning electron microscopy, but they only examined a small number of oocytes. However, Sathananthan et al. (1986) reported that abnormal spermatozoa or spermatozoa with immature nuclei were observed within the ZP. Studies with the zona-free hamster egg penetration test also suggest that morphologically abnormal spermatozoa do not have the same fertilizing ability as those with normal morphology (Rogers et al., 1983; Shalgi et al., 1985; Marsh et al., 1987). There is a negative relationship between percentage abnormal morphology, particularly for pyriform-headed spermatozoa, and the ability to penetrate zona-free hamster eggs (Shalgi et al., 1985; Kruger et al., 1988b).

In mice, abnormal spermatozoa bind to the ZP of oocytes at a frequency significantly lower than their presence in the insemination medium. However, when the percentage of abnormal spermatozoa was very high in the insemination medium, no significant difference existed between frequencies of abnormal spermatozoa bound to the ZP and in the insemination medium (Kot \& Handel, 1987). In the present study, using the conventional method for assessing spermatozoal morphology under $1000 \times$ magnification with oil immersion, we found that abnormal spermatozoa bind to the ZP at significantly lower rates than normal spermatozoa.

We expected that the results of measurement of the head dimensions of spermatozoa would show a consistent pattern of changes towards a more uniform size on the ZP, but this was not so. Some subjects with spermatozoa with the most extreme average measurements in the insemination medium had more extreme values on the ZP. For example, samples with the longest average spermatozoon head length in the insemination medium had even longer average spermatozoon head length on the zona. However, overall the present study shows that length, ratio of length to width and area of the heads of spermatozoa in the insemination medium were larger in patients with samples with poor morphology than in those with good morphology. The average head width of spermatozoa in the insemination medium and bound to the ZP in the poor morphology group was smaller than in the good morphology group. These results indicate that spermatozoa in the insemination medium and bound to the ZP had longer and narrower heads in the poor morphology group than in the good morphology group. The width and area of the heads of spermatozoa bound to the ZP were significantly larger and the ratio of length to width was smaller than for spermatozoa in the insemination medium. This suggests that spermatozoa bound to the ZP are more closely oval in shape. Further studies of objective morphology of spermatozoa on the zona should be useful in indicating the characteristics of spermatozoa with the best fertilizing potential.

The present study further confirms that the morphology of spermatozoa is strongly correlated with fertilization rates in vitro. Even if there was a high frequency of abnormal spermatozoa bound to the ZP in patients with spermatozoa with poor morphology in the insemination medium, there was usually very poor fertilization. However, as shown in previous studies, there are exceptions, one patient, with very few spermatozoa with normal morphology bound to the ZP, did fertilize five oocytes. These outliers are intriguing but may arise merely by chance. Although it is not known if the abnormal spermatozoa bound to the ZP can interfere with the binding or penetration of the ZP by normal spermatozoa, improvement of methods for selection of high proportions of spermatozoa with normal morphology for inseminating oocytes may improve fertilization rates in vitro, particularly in patients with samples with very poor morphology.

In summary, spermatozoa with normal morphology bind to the human $\mathrm{ZP}$ at much higher rates than those with poor morphology. The normal spermatozoa-ZP binding rate is strongly related to the fertilization rate in vitro. Some abnormally shaped spermatozoa, such as those with small oval and pyriform heads, can bind to the $\mathrm{ZP}$ but at low rates. The rate of binding of spermatozoa with pyriform heads is inversely related to the fertilization rate. The results of measurement of head dimensions suggest that spermatozoa with good morphology have larger width and area than those with poor morphology. Finally, objective characterization of morphology of spermatozoa bound 
to the ZP may provide standards for classification of normal morphology to be used in routine semen analysis.

We would like to thank all the scientists in IVF laboratory for collecting the failed fertilized oocytes for this study. Mingli Liu for technical assistance and the Royal Women's Hospital Research Committee for financial support.

\section{References}

Ahlgren, M., Bostrom, K. \& Malmqvist, R. (1974) Sperm transport and survival in women with special reference to the Fallopian tube. In Sperm Transport, Survival and Fertilizing Ability in Vertebrates, vol. 26, pp. 183-200. Eds E. S. E. Hafez \& C. G. Thibault. INSERM, Paris.

Aitken, R.J. \& Elton, R.A. (1984) Significance of Poisson distribution theory in analysing the interaction between spermatozoa and zona-free hamster oocytes. J. Reprod. Fert. 72, 311-321.

Andolz, P., Bielsa, M.A., Genesca, A., Benet, J. \& Egozcue, J. (1987) Improvement of sperm quality in abnormal semen samples using a modified swim-up procedure. Human Reprod. 2, 99-101.

Armitage, P. \& Berry, G. (1987) Statistical Methods in Medical Research, pp. 60, 403. Blackwell Scientific Publishers, Oxford.

Asch, R.H. (1976) Laparoscopic recovery of sperm from peritoneal fluid in patients with negative or poor Sims Huhner test. Fert. Steril. 27, 1111-1114.

Bergman, P. (1955) Sperm migration and its relation to the morphology and motility of spermatozoa. Int. J. Fert. 1, 45-54.

Chan, S.Y.W., Wang, C., Chan, S.T., Ho, P.C., So, W.W.K., Chan, Y.F. \& Ma, H.K. (1989) Predictive value of sperm morphology and movement characteristics in the outcome of in vitro fertilization of human oocytes. $J$. in vitro Fert. Embryo Transfer 6, $142-148$.

Dadoune, J.P. (1988) Ultrastructural abnormalities of human spermatozoa. Human Reprod. 3, 311-318.

Dadoune, J.P., Mayaux, M.J. \& Guihard-Moscato, M.L. (1988) Correlation between defects in chromatin condensation of human spermatozoa stained by aniline blue and semen characteristics. Andrologia 20, $211-217$.

Fredricsson, B. \& Bjork, G. (1977) Morphology of postcoital spermatozoa in the cervical secretion and its clinical significance. Fert. Steril. 28, 841-845.

Hanson, F.W. \& Overstreet, J.W. (1981) The interaction of human spermatozoa with cervical mucus in vivo. Amer. J. Obstet. Gynec. 140, 173-177.

Hinting, A., Comhaire, F., Vermeulen, L., Dhont, M., Vermeulen, A. \& Vandekerckhove, D. (1990) Value of sperm characteristics and the result of in vitro fertilization for predicting the outcome of assisted reproduction. Int. J. Androl. 13, 59-66.

Jeulin, C., Soumah, A. \& Jouannet, P. (1985) Morphological factors influencing the penetration of human sperm into cervical mucus in vitro. Int. $J$. Androl. 8, 215-223.

Jeulin, C., Feneux D., Serres, C., Jouannet, P., GuilletRosso, F., Belaisch-Allar, J., Frydman, R. \& Testart,
J. (1986) Sperm factors related to failure of human in vitro fertilization. J. Reprod. Fert. 76, 1-11.

Kot, M. C. \& Handel, M.A. (1987) Binding of morphologically abnormal sperm to mouse egg zonae pellucida in vitro. Gamete Res. 18, 57-66.

Kruger, T.F., Menkveld, R., Stander, F.S.H., Lombard, C.J., Van der Merwe, J.P., van Zyl, J.A. \& Smith, K. (1986) Sperm morphological features as a prognostic factor in in vitro fertilization. Fert. Steril. 46, 1118-1123.

Kruger, T.F., Acosta, A.A., Simmons, K.F., Swanson, R.J., Matta, J.F. \& Oehninger, S. (1988a) Predictive value of abnormal sperm morphology in in vitro fertilization. Fert. Steril. 49, 112-117.

Kruger, T.F., Swanson, R.J., Hamilton, M., Simmons, K.F., Acosta, A.A., Matta, J.F., Oehninger, S. \& Morshedi, M. (1988b) Abnormal sperm morphology and other semen parameters related to the outcome of the hamster oocyte human sperm penetration assay. Int. J. Androl. 11, 107-113.

Le Lannou, D. \& Blanchard, Y. (1988) Nuclear maturity and morphology of human spermatozoa selected by Percoll density gradient centrifugation or swim-up procedure. J. Fert. Steril. 84, 551-556.

Liu, D.Y. \& Baker, H.W.G. (1988) The proportion of sperm with poor morphology but normal intact acrosome detected with Pisum sativum agglutinin and fertilization in vitro. Fert. Steril. 50, 288-293.

Liu, D.Y. \& Baker, H.W.G. (1990a) Relationships between human sperm acrosin, acrosome, morphology and in vitro fertilization. Human Reprod. 5, 298-303.

Liu, D.Y. \& Baker, H.W.G. (1990b) Inducing the human acrosome reaction with a calcium ionophore A23187 decreases sperm-zona pellucida binding with oocytes that failed to fertilize in vitro. J. Reprod. Fert. 89, 127-134.

Liu, D.Y., Du Plessis, Y., Nayudu, P.L., Johnston, W.I.H. \& Baker, H.W.G. (1988) The use of in vitro fertilization to evaluate putative tests of human sperm function. Fert. Steril. 49, 272-277.

Liu, D.Y., Clarke, G.N., Lopata, A., Johnston, W.I.H. \& Baker, H.W.G. (1989a) A sperm-zona pellucida binding test and in vitro fertilization. Fert. Steril. 52, 281-287.

Liu, D.Y., Lopata, A., Johnston, W.I.H. \& Baker, H.W.I. (1989b) Human sperm-zona pellucida binding, sperm characteristics and fertilization in vitro. Human Reprod. 4, 396-701.

Marsh, S.K., Bolton, V.N. \& Braude, P.R. (1987) The effect of morphology on the ability of human spermatozoa to penetrate zona-free hamster oocytes. Human Reprod. 2, 499-503. 
Moghissi, K.S. (1977) Sperm migration through the human cervix. In The Uterine Cervix in Reproduction, pp. 146-165. Eds V. Insler \& G. Bettendorf. Georg Thieme Publishers, Stuttgart.

Mortimer, D., Leslie, E.E., Kelly, R.W. \& Templeton, A.A. (1982) Morphological selection of human spermatozoa in vivo and in vitro. J. Reprod. Fert. 64, 391-399.

Perry, G., Glezerman, M. \& Insler, V. (1977) Selective filtration of abnormal spermatozoa by the cervical mucus in vitro. In The Uterine Cervix in Reproduction, pp. 146-165. Eds V. Insler \& G. Bettandorf. Georg Thieme Publishers, Stuttgart.

Pousette, A., Akerlof, E., Rosenborg, L. \& Fredricsson, B. (1986) Increase in progressive motility and improved morphology of human spermatozoa following their migration through Percoll gradients. Int. J. Androl.9, $1 \sim 13$.

Ragni, G., Dipietro, R., Bestettl, O., De Lauretis, L., Olivares, D. \& Guercilena, G. (1985) Morphological selection of human spermatozoa in cervical mucus 'in vitro'. Andrologia 17, 508-512.

Rogers, B.J., Bentwood, B.J., Van Campden, H., Helmbrecht, G., Soderdahl, D. \& Hale, R.W. (1983) Sperm morphology assessment as an indicator of human fertilizing capacity. J. Androl. 4, 119-125.
Sathananthan, A.H., Trounson, A.O. \& Wood, C. (1986) Atlas of Fine Structure of Human Sperm Penetration, Eggs and Embryos Cultured In Vitro, pp. 49-83. Praeger Scientific, Philadelphia.

Scott, R.T., Oehninger, S.C., Menkveld, R., Veeck, L.L. \& Acosta, A.A. (1989) Critical assessment of sperm morphology before and after double wash swim-up preparation for in vitro fertilization. Arch. Androl. 23, 125-129.

Shalgi, R., Dor, J., Rudak, E., Lusky, A., Goldman, B., Mashiach, S. \& Nebel, L. (1985) Penetration of sperm from teratospermatozoaic men into zona-free hamster eggs. Int. J. Androl. 8, 285-294.

Soupart, P. \& Strong, P.A. (1974) Ultrastructural observations on human oocytes fertilized in vitro. Fert. Steril. 25, 11-14.

Sundstrom, P. (1984) Interaction between human gametes in vitro: a scanning electron microscopic study. Arch. Androl. 13, 77-85.

World Health Organization (1987) WHO Laboratory Manual for Examination of Human Semen and SemenCervical Mucus Interaction, pp. 1-12. Cambridge University Press, Cambridge.

Received 11 September 1990 